\title{
Risk Distribution Characteristics and Optimization of Short Weaving Area for Complex Municipal Interchanges
}

\author{
Yonggang Liao $\mathbb{D},{ }^{1}$ Yong Yang $\mathbb{D}^{1},{ }^{1}$ Zhenzhong Ding $\left(\mathbb{D},{ }^{2}\right.$ Kaimin Tong $\mathbb{D}{ }^{1}$ \\ and Yanjie Zeng $\mathbb{D}^{2}$ \\ ${ }^{1}$ Guangzhou Municipal Engineering Design \& Research Institute Co., Ltd., Guangzhou 510000, China \\ ${ }^{2}$ School of Civil Engineering and Transportation, South China University of Technology, Guangzhou 510000, China \\ Correspondence should be addressed to Yanjie Zeng; 201510101199@mail.scut.edu.cn
}

Received 10 February 2021; Revised 17 March 2021; Accepted 12 April 2021; Published 27 April 2021

Academic Editor: Xinqiang Chen

Copyright ( 92021 Yonggang Liao et al. This is an open access article distributed under the Creative Commons Attribution License, which permits unrestricted use, distribution, and reproduction in any medium, provided the original work is properly cited.

\begin{abstract}
This paper is focused on analyzing the risk distribution characteristics in short weaving areas of urban interchanges. The study was carried out on merge-diverge weaving areas with different lengths of $350 \mathrm{~m}, 450 \mathrm{~m}$, and $550 \mathrm{~m}$. To evaluate and identify the risk, the average speed, speed standard deviation, acceleration range, and average absolute value of acceleration were selected as indicators. Vissim simulation was applied to collect the identification indicator value of 21 typical lane sections. The results show that the risk is concentrated at the $3 / 4$ section and exit section of the outer lane. The vehicle-operating status of the inner and middle lanes is almost unaffected. The operating speed of the outer lane is approximately $4 / 5$ of the same position in the inner lane at $3 / 4$ of the length of the weaving segment, while the speed standard deviation is approximately 2 times greater, and the acceleration range is approximately $2-3$ times greater. Moreover, the acceleration of the average absolute value is also approximately 2-3 times greater. To balance the risk distribution, an optimization method is proposed based on the result analysis. Compared with the original design, the results show that a reasonable method of traffic organization for the complex weaving area can effectively improve the risk distribution in the weaving area and reduce the high peak of risk concentration. These results provide a basis for the optimization method and traffic organization of short weaving areas of municipal interchanges.
\end{abstract}

\section{Introduction}

With the rapid expansion of the urban landscape, suburban expressways in China that originally served transit traffic have changed to serving the coexistence of transit and service traffic. With the termination of the freeway toll period, the transformation of existing freeway interchanges to municipal interchanges has become an important trend. Freeway interchanges often occupy a huge area. To integrate urban ecological land and save land capital, urban interchanges have the characteristics of concentrated separation and confluence, dense weaving, and so on, forming a large number of complex municipal interchange entrance and exit short weaving areas [1]. In such short weaving areas, vehicle lanes change frequently, which leads to traffic jams or frequent accidents. At present, short weaving areas have become accident-intensive with concentrated risk in urban interchanges [2].
Currently, researchers studying weaving area safety mainly concentrate on the impact of traffic characteristics on the weaving area risk characteristics and the determination of dangerous segments in weaving areas [3-8]. In terms of risk and capacity analysis of entrance and exit weaving areas, Lord and Bonneson [9] found that there were more crashes on crossroad off-ramps than crossroad on-ramps by a ratio of 1.5, and non-free-flow ramps had twice as many crashes as other ramp types. Hossain and Muromachi [10] used detectors to collect high-resolution traffic data in Japan for identifying the factors affecting collisions and concluded that the collision density near urban expressway ramps is higher than that of urban basic expressway segments. Using traffic monitoring probes and detectors, Kusuma et al. $[11,12]$ analyzed the two weaving segments between junctions 41 and 43 of the M1 motorway, and the results showed that approximately $1 / 4$ of the interweaving 
behaviors occurred 50-100 m before the junction. Zhao [13] analyzed the conflict types and concentrated areas in the upstream, middle, and downstream of the interchange tributary area. Ming [14] analyzed the characteristics of traffic flow in a merging area in China using conflict evaluation indexes, for example, traffic flow speed and vehicle lane change characteristics. It was proved that the confluence of vehicles had the greatest impact on the outer mainline lane (TL). Chi and He [15] used conflict probability and lane change risk as evaluation indicators, combined with the gray clustering evaluation method, to analyze safety in the weaving area, and concluded that the outer lane in the weaving area is the most dangerous of all lanes. Ma et al. [16] used a traffic guidance method based on a self-organizing critical state, to optimize for traffic congestion of neighbor weaving segments. The software simulation results showed that the optimized design can reduce the delay of neighbor weaving segments. Li et al. [17] analyzed lane-changing behaviors and optimized the lane-changing strategies in the upstream segments to improve the road safety of the ramp areas.

However, research on spatial distribution characteristics of risk in municipal interchange short weaving areas is rare. The configuration and alignment of the road also have a greater impact on traffic safety. Wang et al. [18, 19] analyzed the road safety of expressways and highways under different alignment combination conditions. Therefore, in the present paper, the common weaving area configuration, that is, a three-lane and ramp double-in, single-out urban interchange with auxiliary lanes, is analyzed in this paper [20]. Using Vissim simulation software, average speed, speed standard deviation, acceleration range, and acceleration of the average absolute values are selected as indicators to characterize risk and conflicts. The spatial distribution characteristics of the internal risk in the short weaving segment are then explored. According to the risk spatial characteristics, the traffic optimization method is proposed to improve the risk distribution of the weaving area. The research results can provide the basis for the optimization method of the facilities and traffic organization in the short weaving areas of municipal interchanges.

The remainder of this paper is organized as follows. In Section 2, part 1 selects the indicators for risk analysis, while part 2 is the determination of simulation experiment parameters. In Section 3, part 1 is the analysis of the experimental results, while part 2 proposes an optimization method, and comparisons are provided in part 3. Section 4 concludes the paper.

\section{Materials and Methods}

2.1. Risk Indicators. Objectivity, comprehensiveness, and practicality should be considered as principles for risk evaluation indexes [21]. In the weaving area, lane change behavior is random, including when and where to change $[22,23]$. Vissim simulation cannot detect the lane changing behavior distribution of the weaving area based on sections. However, it can only analyze the lane changing situation of the whole weaving area. Therefore, speed and acceleration related indicators with high detection efficiency and accuracy have been introduced to analyze risks in the paper.

2.1.1. Average Speed. The vehicles in the weaving area expect to pass through the weaving area smoothly at a certain speed $[24,25]$. Accordingly, maintaining a relatively stable speed is beneficial to keeping the service traffic volume as close as possible to the designed capacity. The average speed of the cross-section along the road space is commonly used as an index to evaluate the degree of the cross-section risk [26-28]. More specifically, the average speed reflects the influence of the weaving traffic flow on the vehicle in the weaving area. When the traffic flow passes through the data detection section, the average vehicle speed is closer to or exceeds the design speed. This means that the traffic flow at the section is less affected by the flow path of weaving vehicles, which hints at the possibility of traffic conflict is smaller. The average speed is

$$
\bar{V}(s, l)=\frac{1}{n} \sum_{i=1}^{n} V_{i}(t, s, l),
$$

where $n$ is the number of vehicles passing through the detection section; $V_{i}(s, l)$ is the instantaneous speed $V_{t}$ of each vehicle $i$ at the detection section $s$ of different weaving length $l(\mathrm{~m} / \mathrm{s})$.

2.1.2. Speed Standard Deviation. The speed standard deviation reflects the change characteristics of traffic flow in the process of lane changing and overtaking [29]. It also reflects the dispersion of vehicle speed when traffic flows through the weaving segment. Generally, the greater the standard deviation of vehicle speed is, the more disordered the traffic flow is and the lower the safety will be $[30,31]$. The speed standard deviation is

$$
V_{\sigma}(s, l)=\sqrt{\frac{1}{n-1} \sum_{i=1}^{n}\left(V_{i}(t, s, l)-\frac{1}{n} \sum_{i=1}^{n} V_{i}(t, s, l)\right)^{2}} .
$$

2.1.3. Acceleration Range. The acceleration range is represented by the maximum positive and negative acceleration difference. The acceleration range reflects the fluctuation amplitude of acceleration at the certain section and also embodies whether there is a large acceleration-deceleration difference [32]. Based on it, the acceleration range can express the degree that it is affected by traffic changes or jams. With data statistics and processing of the acceleration range at the detection section, the probability of possible risk can be revealed. Acceleration range is 


$$
\begin{aligned}
a_{\max }(s, l) & =\max \left\{a_{1}(t, s, l), \ldots, a_{i}(t, s, l), \ldots, a_{n-1}(t, s, l), a_{n}(t, s, l)\right\}, \\
a_{\min }(s, l) & =\min \left\{a_{1}(t, s, l), \ldots, a_{i}(t, s, l), \ldots, a_{n-1}(t, s, l), a_{n}(t, s, l)\right\}, \\
a_{R}(s, l) & =a_{\max }(s, l)-a_{\min }(s, l),
\end{aligned}
$$

where $a_{i}(t, s, l)$ is the instantaneous acceleration of each vehicle $i$ at the detection section $s$ of different weaving length $l\left(\mathrm{~m} / \mathrm{s}^{2}\right) ; a_{\max }(s, l)$ is the maximum acceleration of each vehicle at the detection section $s$ of different weaving length $l$ $\left(\mathrm{m} / \mathrm{s}^{2}\right) ; a_{\min }(s, l)$ is the maximum deceleration $\left(\mathrm{m} / \mathrm{s}^{2}\right) ; a_{R}$ is the difference of maximum acceleration and deceleration $\left(\mathrm{m} / \mathrm{s}^{2}\right)$.

2.1.4. Average of Absolute Acceleration. The average value will be balanced by the positive and negative acceleration values, which cannot reflect the fluctuation of the acceleration. The average absolute acceleration can successfully reflect the degree of dispersion of acceleration changes. The larger the value is, the faster speed changes at the sections, resulting in increased driving risks. The average of absolute acceleration is

$$
\bar{a}_{B}(s, l)=\frac{1}{n} \sum_{i=1}^{n}\left|a_{i}(t, s, l)\right|,
$$

where $n$ is the number of vehicles passing through each detection section.

In summary, average speed $(\bar{V}(s, l))$, vehicle speed standard deviation $\left(V_{\sigma}(s, l)\right)$, acceleration range $\left(a_{R}(s, l)\right)$, and acceleration of average absolute value $\left(\bar{a}_{B}(s, l)\right)$ have been determined to analyze the risk space characteristics of the weaving area. If two adjacent ramps are close to each other on an expressway, vehicles merge or diverge on a single ramp, which will have an impact on the vehicles in the $\mathrm{TL}$ and adjacent ramps. Therefore, these two ramps and the weaving area between them can be considered as a whole.

2.2. Experiments. The more common TL three-lane, ramp double-entry single-out, and the weaving area structure with auxiliary lanes for research is selected in this paper. Furthermore, the length of the weaving area borrows the maximum weaving length formula proposed in the United States Highway Capacity Manual (HCM 2010). Based on it, the calculation shows that the maximum length is $750 \mathrm{~m}$; meanwhile, the minimum weaving zone length determined by Wang et al. [33] research is $150 \mathrm{~m}$. According to HCM 2010, the length of the weaving segment is approximately equal to the distance between the two adjacent shunt noses. If the length of the weaving segment is too short, the lane change behavior is prone to congestion, and the internal risk cannot be reflected by the speed and acceleration. At the same time, the long length of the weaving segment leads to results in the indicator value reflects the internal risk concentration is not obvious. Therefore, in this study, three weaving lengths of $350 \mathrm{~m}, 450 \mathrm{~m}$, and $550 \mathrm{~m}$ are selected for experimental analysis.
For the design speed of the TL and ramp section of the municipal interchange, the common design speeds of $80 \mathrm{~km} / \mathrm{h}$ and $60 \mathrm{~km} / \mathrm{h}$ are selected, respectively, in this study, and Wang et al. [34] found that the number of accidents with $80 \mathrm{~km} / \mathrm{h}$ design speeds was more than three times accidents with the design speed of $100 \mathrm{~km} / \mathrm{h}$ and $120 \mathrm{~km} / \mathrm{h}$ in Guangdong Province freeways. According to the design requirements of Tables 1 and 2 of the TL and ramp traffic volume in the specification, to prevent vehicle jams, so the TL and ramp traffic volume range is reduced by $2 / 3$ of the original design traffic $[35,36]$. Finally, the traffic volume when the two-lane ramp adopts the design speed of $60 \mathrm{~km} / \mathrm{h}$ is $1500 \mathrm{veh} / \mathrm{h} / \mathrm{ln}$, and the main three-lane adopts the design speed of $80 \mathrm{~km} / \mathrm{h}$ is $2200 \mathrm{veh} / \mathrm{h} / \mathrm{ln}$ [37-39]. Through experiments, it is found that there are still serious congestion conditions in some road segments. After debugging, the final experimental traffic volume is set as $1800 \mathrm{veh} / \mathrm{h} / \mathrm{ln}$ for the TL and $1400 \mathrm{veh} / \mathrm{h} / \mathrm{ln}$ for the ramp traffic. When vehicles in a weaving area experience traffic conflicts due to changing lanes, there is not only a traffic risk, but the capacity of the weaving area is also affected. Therefore, based on the previously mentioned research content, in this paper, research on the risk and traffic efficiency of the weaving area is conducted, and relevant indicators representing traffic efficiency and risk characteristics of weaving areas are determined.

To avoid traffic jams, we determine that the interleaving traffic ratio and interleaving ratio are 0.1 and 0.5 respectively.

The data detection sections have been set every $1 / 4$ section from merging section to diverging section along through lanes, ramp, and auxiliary lane. Ultimately, 21 data detection sections are present in our paper (see Figure 1).

Without traffic control in the weaving area, ding to the characterization index of determining the risk section, selects the weaving length of $350 \mathrm{~m}, 450 \mathrm{~m}$, and $550 \mathrm{~m}$, respectively, then simulates and analyses the weaving segment configuration with three lanes TL, double-entry-single-exit ramp, and auxiliary lane.

Furthermore, the acceleration and velocity data of each vehicle are counted and collected, which are obtained from the data detection section files. The four major characterization indexes at the data detection sections are summarized in Tables S1 to S3.

\section{Result Analysis and Discussion}

3.1. Indicator Characteristics Analysis. For the layout of the ramp double lane entrance data detection sections, the right line of traffic flows directly into the auxiliary lane, so this drawing takes the ramp right line exit as the auxiliary lane entrance data detection section index value, and the left line is used to compare the right line index value. According to the statistics of $350 \mathrm{~m}, 450 \mathrm{~m}$, and $550 \mathrm{~m}$ weaving area of the risk characterization index value, for each $1 / 4$ interval 
TABLE 1: Ramp design capacity of basic sections.

\begin{tabular}{lcccccc}
\hline Ramp design speed $(\mathrm{km} / \mathrm{h})$ & 80 & 70 & 60 & 50 & 40 \\
\hline \multirow{2}{*}{ Design capacity } & Single lane & 1500 & 1400 & 1300 & 1200 & 1000 \\
& Double lane & 2900 & 2600 & 2300 & 2000 & 1700 \\
\hline
\end{tabular}

TABle 2: Expressway single-lane service traffic volume.

\begin{tabular}{lccc}
\hline Ramp design speed $(\mathrm{km} / \mathrm{h})$ & 120 & 100 & 80 \\
\hline Traffic capacity of LOS 2 & 1200 & 1150 & 1100 \\
Traffic capacity of LOS 3 & 1650 & 1600 & 1500 \\
\hline
\end{tabular}

section of the TL and auxiliary lane, the single factor level analysis is carried out. Based on the previously mentioned statement, in this paper, Origin software is used to calculate the average speed, standard deviation of vehicle speed, acceleration range, and average absolute value of acceleration by combining the point line graph model. In more detail, each line in the graph represents the index of each lane under different weaving lengths, the abscissa represents the position of the vehicle in the weaving segment, and the ordinate represents the index value. On each lane represented by the ordinate axis, the weaving length from left to right is $350 \mathrm{~m}$, $450 \mathrm{~m}$, and $550 \mathrm{~m}$. The experimental results are shown in Figures 2-5.

3.1.1. Average Speed. In terms of average vehicle speed, the inner lane and middle lane of the TL are less affected by the weaving traffic flow. Therefore, compared with the outer and auxiliary lanes, the average speed condition is higher, whose values are stable between 23 and $25 \mathrm{~m} / \mathrm{s}$. The outer and auxiliary lanes are subject to the lane change of the intertwined traffic flow, which causes the vehicle speed to fluctuate greatly. Compared with the design speed, the average speed of the traffic flow at the entrance to the outer TL is slightly reduced relatively. At the section of $1 / 4$ to $3 / 4$, its speed is reduced by $1 / 5-1 / 4$ relative to the speed of the entrance section. Then, the speed at the exit is reduced to approximately $20 \mathrm{~m} / \mathrm{s}$. As for the $350 \mathrm{~m}$ and $450 \mathrm{~m}$ weaving lengths, the speed from the entrance to the $1 / 2$ section and from the $1 / 2$ section to the exit drops from about $17.5 \mathrm{~m} / \mathrm{s}$ to about $16 \mathrm{~m} / \mathrm{s}$. Due to the increment of lane changing behaviors in the auxiliary and outer lanes as they approach the exit, the vehicle speed from section 3/4 to the exit of the auxiliary and outer lanes is reduced.

3.1.2. Speed Standard Deviation. The speed standard deviation of the inner and middle lanes of TL is above $1.5 \mathrm{~m} / \mathrm{s}$ at the entrance, then, it gradually decreases to between $1.0 \mathrm{~m} /$ $\mathrm{s} \sim 1.5 \mathrm{~m} / \mathrm{s}$ at the $1 / 2$ section, and at last, it increases and becomes still stable between $1.25 \mathrm{~m} / \mathrm{s} \sim 2.5 \mathrm{~m} / \mathrm{s}$ after the $1 / 2$ section. The speed standard deviation of the outer lane is stable at about $2.0 \mathrm{~m} / \mathrm{s}$ in the entrance. As the section position advances, the speed standard deviation basically increases and fluctuates between $2.5 \mathrm{~m} / \mathrm{s}$ and $4.5 \mathrm{~m} / \mathrm{s}$ at the $3 / 4$ section and exit section. The reason mainly is related to the vehicle changing lanes in the auxiliary lane with lower speed.
The index values of the auxiliary lane from the entrance to the $1 / 2$ section are stable within the range of $0.75-1.25 \mathrm{~m} / \mathrm{s}$, which are lower than those of different lanes and positions. At the same time, the index values from the $1 / 2$ section to the exit gradually increase and are stable at $2 \mathrm{~m} / \mathrm{s}$ of the exit. Regarding the results of the speed standard deviation analysis, the speed of vehicles coming into the main lane from the ramp is lower than that of the TL, so the fluctuation range of the vehicle speed will be lower than that of the TL. The closer the vehicles are to the exit of the auxiliary lane, the more the vehicles changing lanes, which leads to the increment at that position.

3.1.3. Acceleration Range. For the acceleration range, the higher the range at the data detection section, the higher the probability of traffic conflicts at that location. The range of the inner and middle lanes of the TL fluctuates within $5 \mathrm{~m} / \mathrm{s}^{2}$; furthermore, the range of the middle lane relative to the inner lane is generally small. Relative to other lanes at the same positions of the TL, the acceleration range of the outer lanes are overall larger. For example, there are several section locations where the acceleration range is higher than $7 \mathrm{~m} / \mathrm{s}^{2}$. In particular, three acceleration range values are significantly higher than $7 \mathrm{~m} / \mathrm{s}^{2}$ in the $350 \mathrm{~m}$ weaving length model, which occurred at the entrance, $1 / 2$ section, and $3 / 4$ section. For the auxiliary lane, the acceleration range values stabilize below $4 \mathrm{~m} / \mathrm{s}^{2}$ under the $450 \mathrm{~m}$ and $550 \mathrm{~m}$ weaving length models. However, the index values are above $4 \mathrm{~m} / \mathrm{s}^{2}$ at the $1 /$ 2 and $3 / 4$ sections under the $350 \mathrm{~m}$ model. Because the design speed is different when the ramp and TL are inputted, the speed difference between the outer and auxiliary lanes leads to a large acceleration value when changing lanes. Furthermore, since the speed of the vehicle entering the auxiliary lane from the ramp is smaller than that of the TL, the acceleration range difference is also smaller than that of the outer lane.

3.1.4. Average of Absolute Acceleration. This indicator reflects the fluctuation range of the acceleration index at the data detection section. The larger the average absolute value of acceleration, the larger the range of acceleration, the more unsafe the condition. For the inner and middle lanes, the indicator values are stable within $0.4 \mathrm{~m} / \mathrm{s}^{2}$. The outer lane fluctuates greatly, and the maximum value of all the weaving lengths appears at the $3 / 4$ section of the $350 \mathrm{~m}$ model, which reaches more than $1 \mathrm{~m} / \mathrm{s}^{2}$. Regarding the auxiliary lane, the index values are always at a low level from the entrance to the $3 / 4$ section, which are stable at $0.2 \mathrm{~m} / \mathrm{s}^{2}$, and rise to about $0.4 \mathrm{~m} / \mathrm{s}^{2}$ at the exit section. Furthermore, the acceleration of the average absolute value is also small relative to the outer lane. Due to the frequent acceleration and deceleration caused by the different design speeds at the entrance of the ramp and TL, there are speed differences between the outer and auxiliary lanes during the lane change.

Through the analysis of the lane positions and four characterization indexes, it can be concluded that, in the urban complex interchange short weaving area, the risk probability at the $3 / 4$ section and exit section of the outer 




FiguRe 1: Location of data detection sections.



FIGURE 2: Analysis of average vehicle speed.

lane is the highest, which is the key node position of risk control and optimization. As for the auxiliary lane, because the speed of the vehicle entering from the ramp is low, the fluctuation range of average acceleration absolute value and acceleration range are smaller than those of other lanes, thereby reducing the probability of risk and conflicts.

3.2. Optimal Method. Based on the results of the indicators value analysis, we propose a method to optimize the probability of occurrence of risk and conflicts in key node position. Near the exit of the ramp, the weaving traffic without lane change will choose the deceleration lane change, which results in the fact that the rear straight vehicle needs to decelerate to avoid the occurrence of conflict. At the same time, the driver has the recognition distance for the exit direction in the weaving area. Some drivers will decide to change the lane to drive to the exit direction near the exit, and this behavior leads to increased risk [40].

According to the freeway entrance and exit standardsetting guide [41] released by Guangdong province, it requires that the length of the solid line segment of the dividing line between the inner lane and the middle lane is

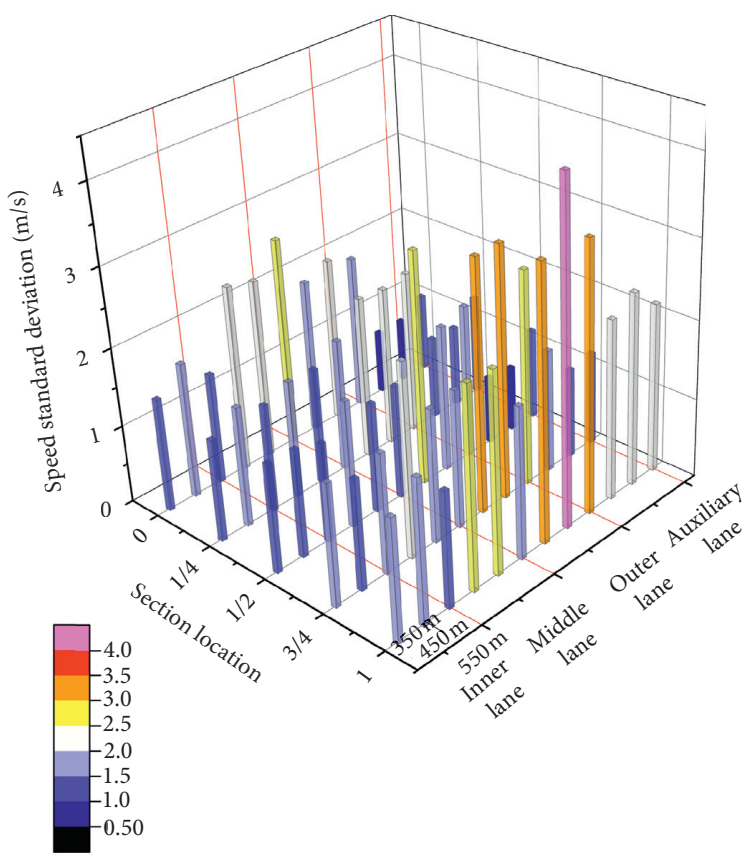

FIgURE 3: Analysis of speed standard deviation.

from the starting point of the gradient section to the end of the guardrail. The same requirement is between the middle lane and the outer lane. At the same time, the solid line section of the inner and middle lanes should extend $L$ forward. However, it is set for the entrance and exit of the expressway, and the length of the solid line segment is not applicable in the short weaving area. Kang, L. et al. [42] showed that the vehicle should have the corresponding lane change length when changing lane and assumed that the vehicle completes the lane change before the solid line segment of the inner lane and enters the middle lane, to ensure it can smoothly change lane into the outer lane. The lane change length is required to be shorter than $L$.

The lane change length includes the vehicle acceleration speed matching length $l_{1}$ and the distance travelled to confirm and merge into the middle lane $1_{2}$. Tend to be safer rounding to get $L=l_{1}+l_{2}=0+50=50 \mathrm{~m}$ [43]. Moreover, to ensure that the solid segment of the inner and middle lanes is not too long, there should be a $L$ lane change length, so this method sets the appropriate length to $1 / 5(\mathrm{~T}-\mathrm{L})$. Moreover, compared with the outer and auxiliary lanes, vehicles in the middle and inner lanes are in better driving conditions according to the analysis of the experimental results. According to the driving conditions, the method 


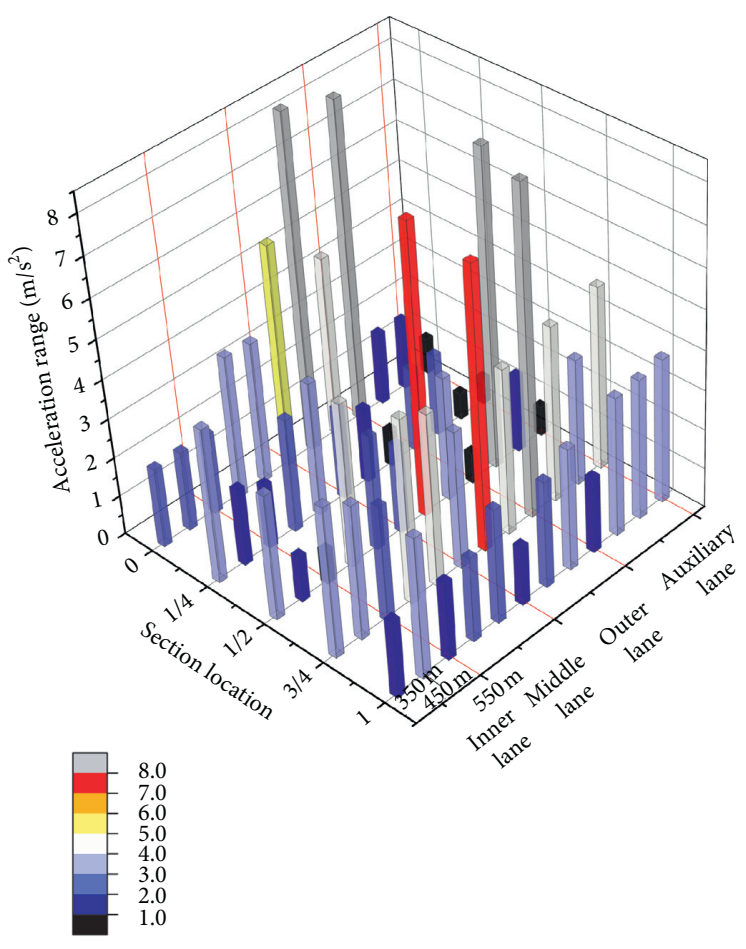

Figure 4: Analysis of acceleration range.

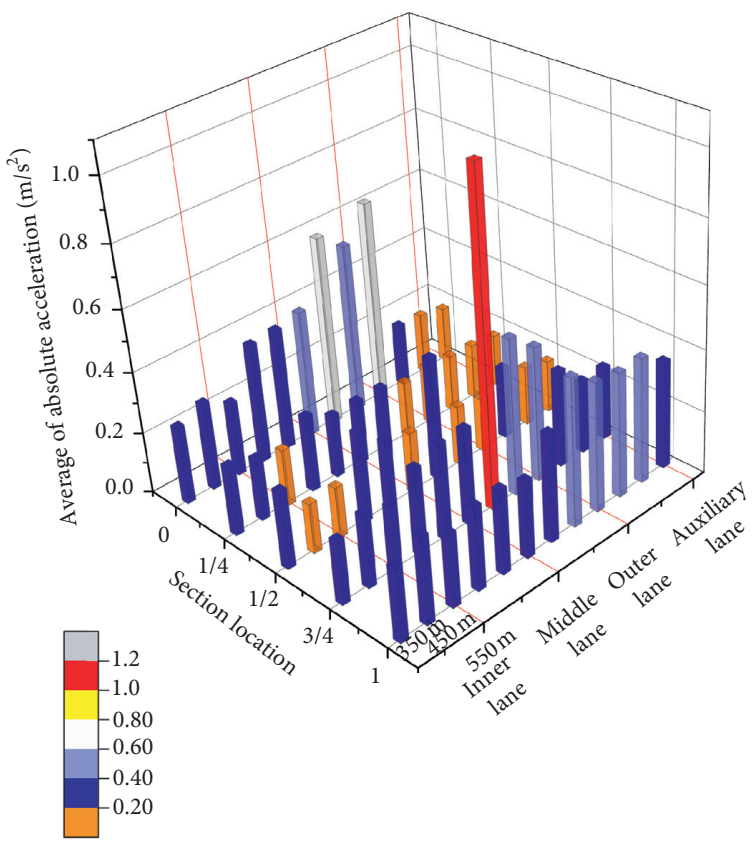

FIGURE 5: Acceleration of average absolute value analysis.

should be allowed in the solid section of the unilateral vehicles, which can change their direction from the outer lane to the middle lane and from the middle lane to the inner lane. The proposed traffic optimization method is shown in Figure 6.

After calculating, the lengths of the solid line segment of the middle and outer lanes under the weaving lengths of
$350 \mathrm{~m}, 450 \mathrm{~m}$, and $550 \mathrm{~m}$ are $60 \mathrm{~m}, 80 \mathrm{~m}$, and $100 \mathrm{~m}$ respectively.

3.3. Indicators Optimal Effect. Using Vissim to simulate the model after the optimization of the method, the advantageous characteristics of the method are analyzed by comparing the characterization indexes. The index difference analysis is shown in Figures 7-10.

3.3.1. Average Speed. After the implementation of traffic optimization, for the $3 / 4$ and exit sections, speed increments are more than the decreases. More specifically, the speed of the outer lane with the length of $450 \mathrm{~m}$ and $550 \mathrm{~m}$ weaving area reduces within the range of $0.5-1 \mathrm{~m} / \mathrm{s}$. At the same time, the speed of the auxiliary lane at the exit section increases within $0.5 \mathrm{~m} / \mathrm{s}$, while the speed of the $3 / 4$ section and exit section of the outer lane in the $550 \mathrm{~m}$ model decreases more than $0.5 \mathrm{~m} / \mathrm{s}$ and $1.5 \mathrm{~m} / \mathrm{s}$, respectively.

The main reason is that the one-sided solid line segment between the middle and outer lanes of the $550 \mathrm{~m}$ model starts near this position. Given the driver's path decision of deceleration, this approach will lead to a certain drop in the vehicle speed at this position.

3.3.2. Speed Standard Deviation. For the $3 / 4$ and exit sections, the standard deviation values of speed were mainly reduced. The index values of the outer lane are reduced obviously. The weaving length of the $550 \mathrm{~m}$ model, especially, reaches the maximum decline value of more than $0.5 \mathrm{~m} / \mathrm{s}$ in the $3 / 4$ section. At the same time, the drop of the outer lane at the length of $450 \mathrm{~m}$ reaches more than $0.8 \mathrm{~m} / \mathrm{s}$ in the exit section.

The prohibition of lane changes into outer or middle lanes leads to fewer vehicles merging and weaving, which ensures the safety of the outer lane and auxiliary lane of the exit section. Besides, the speed increase at the outer lane of the length of $550 \mathrm{~m}$ is more than $0.6 \mathrm{~m} / \mathrm{s}$, which may be caused by the weaving of the outer and auxiliary lanes.

3.3.3. Acceleration Range. In general, most lane index values decrease under different weaving lengths. For the outer and auxiliary lanes, the descent values fluctuate in the range of $2-6 \mathrm{~m} / \mathrm{s}^{2}$. Furthermore, this method reduces the large acceleration range at the risk concentration locations. More specifically, the $350 \mathrm{~m}$ and $550 \mathrm{~m}$ model indicator values have a large decline of $2 \mathrm{~m} / \mathrm{s}^{2}$ and $5 \mathrm{~m} / \mathrm{s}^{2}$, respectively. The acceleration range at the exit section fluctuates slightly within the range of $2 \mathrm{~m} / \mathrm{s}^{2}$.

Mainly after the implementation of traffic optimization, in the original risk of $3 / 4$ section of the inner and middle lanes, vehicles are prohibited to enter the outer lane, thus reducing the interweaving behaviors caused by the deceleration of the routing decision of the vehicle near the exit position. 


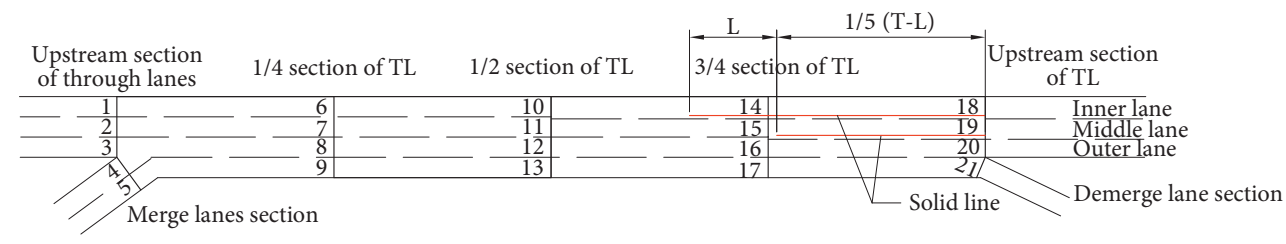

FIGURE 6: Schematic diagram of weaving area optimization.



FIgURE 7: The average speed difference between the optimized method and the original design.

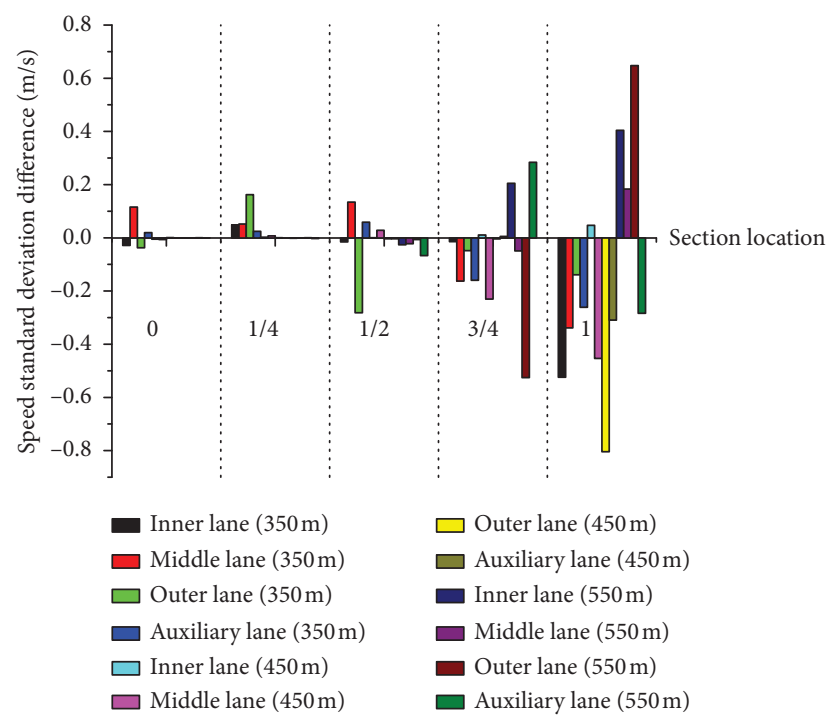

FIGURE 8: The speed standard deviation difference between the optimized method and the original design.

3.3.4. The Average of Absolute Acceleration. In the $3 / 4$ section and exit section, the index values are mainly reduced under different weaving lengths. In the $350 \mathrm{~m}$ and $550 \mathrm{~m}$ models of the $3 / 4$ section, the indexes produce a decrease

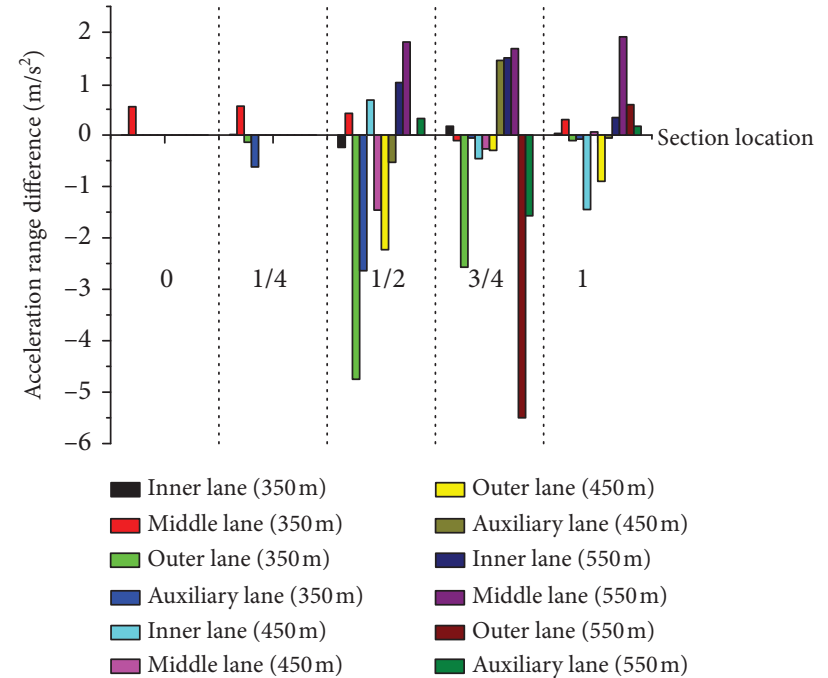

FIgURE 9: The acceleration range difference between the optimized method and the original design.

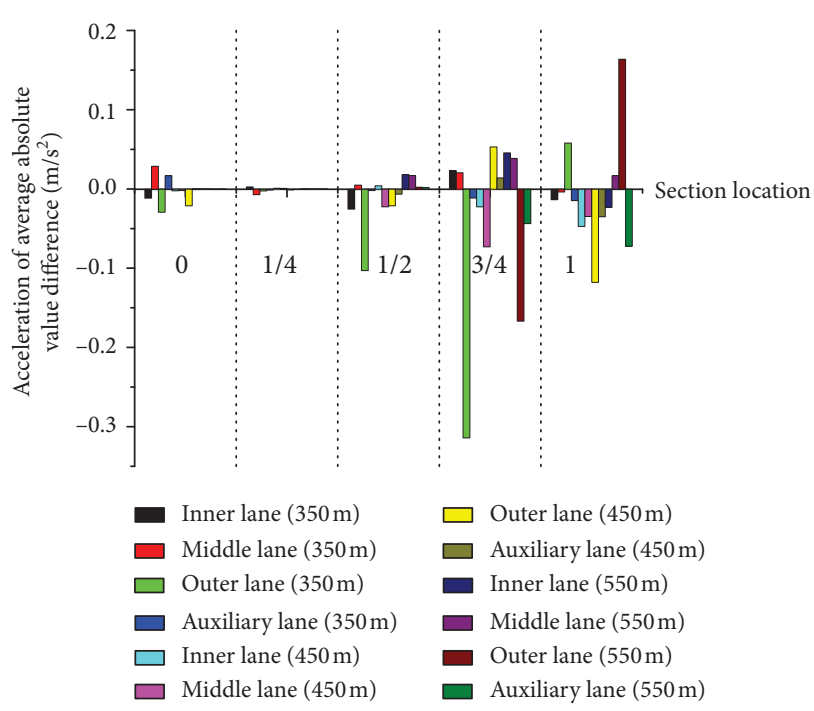

FIgURE 10: The acceleration of average absolute value difference between the optimized method and the original design.

higher than $0.1 \mathrm{~m} / \mathrm{s}^{2}$ and $0.3 \mathrm{~m} / \mathrm{s}^{2}$, which significantly reduces the probability of occurrence at the risk concentration position. At the same time, the indicator values of $350 \mathrm{~m}$ and $550 \mathrm{~m}$ models exit have increased by no more than $0.1 \mathrm{~m} / \mathrm{s}^{2}$ 
and $0.2 \mathrm{~m} / \mathrm{s}^{2}$, respectively, but the $450 \mathrm{~m}$ model has decreased by more than $0.15 \mathrm{~m} / \mathrm{s}^{2}$.

The main reason is that the inner and middle lane vehicles are prohibited from entering the outer lane at the 3/4 section, where the risk is concentrated, thus reducing the interweaving behaviors caused by routing decisions. At the same time, because the middle and inner lanes have better traffic conditions, and in the outer and auxiliary lanes, vehicles are allowed to merge into the middle and inner lanes, this method is equivalent to distributing the risk occurrence to the entire short weaving segment.

In general, the optimization method distributes the probability of risk occurrence to road segments and lanes with better driving conditions and plays a better role in reducing the risk and conflicts of risk concentration position from the 3/4 section of the outer and auxiliary lanes to the exit. Compared with the original scheme, the optimization method can improve traffic safety in the short weaving area of the city.

Furthermore, this article is based on China's design specifications, and it takes into account the internal safety analysis of the short weaving area between two adjacent interchanges. The applicability of its conclusions to other countries remains to be verified. The effect of the optimization method is based on the increase or decrease of the detection section index value and focuses on the location of risk concentration. There is no further study on the probability of risk occurrence of other detection sections after optimization.

\section{Conclusions}

The location of internal risk in the weaving areas of complex municipal interchanges under different weaving lengths is studied in this paper. Three-lane (TL) and ramp double-in, single-out type interchanges with auxiliary lanes are selected for study, as they comprise the common weaving segment configurations. By combining the risk characteristic sections with four indicators, namely, average speed, speed standard deviation, acceleration range, and acceleration of average absolute value, the risks and conflicts in short weaving areas are analyzed and evaluated. An optimization method is proposed and analyzes the difference between the optimized method and the original design based on the index value. Results show that the risk distribution of weaving areas can be effectively improved, and the peak value of risk concentration areas can be reduced through reasonable optimization of traffic organization design. Such results can provide a reference for the optimization method of facilities and traffic organization in municipal interchange short weaving areas. However, this paper proposes the method for determining and optimizing risk key node position, which is based on China's traffic conditions, and its applicability to other countries in the world has yet to be verified.

In detail, the following conclusions are drawn.

(1) For the weaving area configuration of complex municipal interchanges, speed and acceleration characterization indexes were simulated and analyzed. From the results, it is concluded that the concentrated position of internal risk appears in the 3/4 weaving length and exit position of the TL outer lane.

(2) By comparing the characterization index values of the optimized and original models, results show that the optimization method can improve the standard deviation of vehicle speed, acceleration range, and acceleration of average absolute value condition in the risk concentrated section. Moreover, it can distribute the probability of risk occurrence to the segments with better driving conditions, to facilitate the internal risk equilibrium distribution of urban short weaving areas.

(3) The risk and conflicts of the TL, ramp, and auxiliary lanes within the length of each $1 / 4$ section of the weaving area are researched. In the future, as many data detection sections and other urban weaving segments as possible will be studied to explore a more detailed risk distribution of urban short weaving areas.

\section{Data Availability}

The data used to support the findings of this study are available from the corresponding author upon request.

\section{Conflicts of Interest}

The authors declare that there are no conflicts of interest regarding the publication of this paper.

\section{Acknowledgments}

This work was supported by the National Natural Science Foundation of China (grant no. 51878297, Natural Science Foundation of Guangdong Province (grant no. 2019A1515011477), Fundamental Research Funds for the Central Universities of South China University of Technology (grant no. 2020ZYGXZR093), and Guangdong Provincial Key Laboratory of Modern Civil Engineering Technology (no. 2021B1212040003).

\section{Supplementary Materials}

The Supplementary Materials file summarizes four major characterization indexes at the data detection sections under different weaving lengths of $350 \mathrm{~m}, 450 \mathrm{~m}$, and $550 \mathrm{~m}$ in Tables S1, S2, and S3. (Supplementary Materials)

\section{References}

[1] M. Li, "Research and application of ramp layout of urban elevated expressway "first in, last out"” Urban Roads Bridges and Flood Control, vol. 07, pp. 53-55, 2016.

[2] H. Chen, "Traffic efficiency comparative analysis and optimal design of ramp combinations in urban expressway," Master's Thesis, Shanghai Jiao Tong University, Shanghai, China, 2015.

[3] Z. Wang, Y. Yue, Q. Li, K. Nie, W. Tu, and S. Liang, "Analyzing risk factors for fatality in urban traffic crashes: a case 
study of wuhan, China," Sustainability, vol. 9, no. 6, p. 897 , 2017.

[4] X. Mao, C. Yuan, J. Gan, and S. Zhang, "Risk factors affecting traffic accidents at urban weaving sections: evidence from China," International Journal of Environmental Research and Public Health, vol. 16, no. 9, p. 1542, 2019.

[5] L. Wang and M. Abdel-Aty, "Microscopic safety evaluation and prediction for freeway-to-freeway interchange ramps," Transportation Research Record: Journal of the Transportation Research Board, vol. 2583, no. 1, pp. 56-64, 2016.

[6] M. Montoya-Alcaraz, A. Mungaray-Moctezuma, J. CalderónRamírez, L. García, and C. Martinez-Lazcano, "Road safety analysis of high-risk roads: case study in baja California, méxico," Safety, vol. 6, no. 4, p. 45, 2020.

[7] V. Astarita, C. Caliendo, V. P. Giofrè, and I. Russo, "Surrogate safety measures from traffic simulation: validation of safety indicators with intersection traffic crash data," Sustainability, vol. 12, no. 17, p. 6974, 2020.

[8] X. Sun, K. Lin, P. Jiao, and H. Lu, "The dynamical decision model of intersection congestion based on risk identification," Sustainability, vol. 12, no. 15, p. 5923, 2020.

[9] D. Lord and J. A. Bonneson, "Calibration of predictive models for estimating safety of ramp design configurations," Transportation Research Record: Journal of the Transportation Research Board, vol. 1908, no. 1, pp. 88-95, 2005.

[10] M. Hossain and Y. Muromachi, "Understanding crash mechanism on urban expressways using high-resolution traffic data," Accident Analysis and Prevention, vol. 57, pp. 17-29, 2013.

[11] A. Kusuma, R. Liu, C. Choudhury, and F. Montgomery, "Analysis of the driving behaviour at weaving section using multiple traffic surveillance data," Transportation Research Procedia, vol. 3, pp. 51-59, 2014.

[12] A. Kusuma, R. Liu, and C. Choudhury, "Modelling lanechanging mechanisms on motorway weaving sections," Transportmetrica B: Transport Dynamics, vol. 8, no. 1, pp. 1-21, 2020.

[13] S. Zhao, "Interchange traffic safety model based on traffic conflict technology," Master's Thesis, Southeast University, Jiangsu, China, 2016.

[14] X. Ming, "Traffic safety assessment method of merge area based on the traffic conflict," Master's Thesis, Southeast University, Jiangsu, China, 2017.

[15] J. Chi and Y. He, "Research on the safety evaluation method of weaving segments based on traffic conflict," Transportation Technology and Economy, vol. 22, pp. 27-32+38, 2020.

[16] Q. Ma, S. Zhang, Y. Qiao, and M. Feng, "Traffic guidance selforganization method for neighbor weaving segments based on self-organized critical state," IEEE Access, vol. 8, pp. 171784-171795, 2020.

[17] H. Li, Z. Huang, X. Zou, S. Zheng, and Y. Yang, "VISSIMbased simulation and analysis of upstream segments in ramp areas for optimizing vehicle group lane-changing behaviors," Journal of Advanced Transportation, vol. 2020, Article ID 5983161, 11 pages, 2020.

[18] X. Wang, J. Yao, and Z. Ding, "Highway safety analysis on the influence of continuous degradation of three-dimensional alignment," China Journal of Highway and Transport, vol. 34, pp. 157-166, 2021.

[19] X. Wang, H. Pu, X. Li, Y. Yan, and J. Yao, “A new GNB model of crash frequency for freeway sharp horizontal curve based on interactive influence of explanatory variables," Journal of Advanced Transportation, vol. 2018, Article ID 8973581, 9 pages, 2018 .
[20] S. S. Pulugurtha and J. Bhatt, "Evaluating the role of weaving section characteristics and traffic on crashes in weaving areas," Traffic Injury Prevention, vol. 11, no. 1, pp. 104-113, 2010.

[21] G. Zhou, "Research on the traffic flow characteristic and its influence factor for freeway upgrade section," Master's Thesis, Southeast University, Jiangsu, China, 2014.

[22] W. Hao, Z. Zhang, Z. Gao, K. Yi, L. Liu, and J. Wang, "Research on mandatory lane-changing behavior in highway weaving sections," Journal of Advanced Transportation, vol. 2020, pp. 1-9, 2020.

[23] B. Wang, L. Gao, and Z. Juan, "Analysis of lane changing conflict based on TTA in expressway weaving area," Journal of System Simulation, vol. 30, pp. 3306-3311, 2018.

[24] L. Aarts and I. van Schagen, "Driving speed and the risk of road crashes: a review," Accident Analysis \& Prevention, vol. 38, no. 2, pp. 215-224, 2006.

[25] Z. Cheng, J. Lu, and Y. Li, "Freeway crash risks evaluation by variable speed limit strategy using real-world traffic flow data," Accident Analysis \& Prevention, vol. 119, pp. 176-187, 2018.

[26] S. Tanaka, N. Hasegawa, D. Iizuka, and F. Nakamura, "Evaluation of vehicle control algorithm to avoid conflicts in weaving sections under fully-controlled condition in urban expressway," Transportation Research Procedia, vol. 21, pp. 199-207, 2017.

[27] K. I. Ahmed, Modeling drivers' acceleration and lane changing behavior, PhD Thesis, Massachusetts Institute of Technology, Cambridge, Massachusetts, USA, 1999.

[28] X. Wang, H. Pu, J. Yao, Y. Yan, X. Li, and Z. Zeng, "A novel speed model for safety evaluation of freeway alignment in Euclidean 3D space," Traffic Injury Prevention, vol. 20, no. 4, pp. 392-399, 2019.

[29] C. Xu, X. Wang, H. Yang, K. Xie, and X. Chen, "Exploring the impacts of speed variances on safety performance of urban elevated expressways using GPS data," Accident Analysis \& Prevention, vol. 123, pp. 29-38, 2019.

[30] T. Diao, "Research on the characteristics of traffic flow in the weaving area of interchanges based on traffic safety," Master's Thesis, Southeast University, Jiangsu, China, 2017.

[31] J. Dai, "Traffic safety evaluation of expressway interchanges based on traffic conflict technology," Master's Thesis, Southeast University, Jiangsu, China, 2016.

[32] C. Miyajima, H. Ukai, A. Naito, H. Amata, N. Kitaoka, and K. Takeda, "Driver risk evaluation based on acceleration, deceleration, and steering behavior," in Proceedings of 2011 IEEE International Conference on Acoustics, Speech and Signal Processing (ICASSP), pp. 1829-1832, IEEE, Prague Congress Center, Czech Republic, May, 2011.

[33] Z. Wang, N. Guo, and J. Li, "Simulation to solve the reasonable length of the interweaving area of urban expressways," China and Foreign Highway, vol. 27, pp. 197-201, 2007.

[34] X. Wang, S. Yang, Y. Yan, X. Li, J. Du, and J. Tang, "Analysis on distribution of freeway accidents under various conditions in China," Advances in Mechanical Engineering, vol. 8, no. 8, Article ID 168781401666024, 2016.

[35] X. Chen, J. Lu, J. Zhao, Z. Qu, Y. Yang, and J. Xian, “Traffic flow prediction at varied time scales via ensemble empirical mode decomposition and artificial neural network," Sustainability, vol. 12, no. 9, p. 3678, 2020.

[36] X. Chen, X. Xu, Y. Yang, H. Wu, J. Tang, and J. Zhao, "Augmented ship tracking under occlusion conditions from maritime surveillance videos," IEEE Access, vol. 8, pp. 42884-42897, 2020.

[37] Transportation Research Board, Highway Capacity Manual, Transportation Research Board, Washington, DC, USA, 2010. 
[38] China Highway Engineering Consulting Group Co., Ltd., Design Rules for Highway Interchanges, China Highway Engineering Consulting Group Co., Ltd., Beijing, China, 2014.

[39] Transportation Bureau of the Ministry of Transport, Highway Engineering Technical Standards, Transportation Bureau of the Ministry of Transport, Beijing, China, 2014.

[40] W. Hou, Research on Traffic Operation Characteristics of Small-Distance Urban Interchanges. Master's Thesis, Chongqing Jiaotong University, Chongqing, China, 2019.

[41] Guangdong Provincial Highway Administration Bureau, Highway Entrance and Exit Standard-Setting Guide, Guangdong Provincial Highway Administration Bureau, Guangdong, China, 2016.

[42] L. Kang and X. Huang, "Interchange safety spacing analysis for urban expressways and tunnels," Traffic and Transport, vol. 35, pp. 13-16, 2019.

[43] Y. Zhao, M. Chen, and B. Pan, "Demand analysis of minimum distance between tunnel and interchange exit," Journal of Chang'an University (Natural Science Edition), vol. 31, pp. 68-71+89, 2011. 